\title{
Correlates of Career Priority and Family Priority among Turkish Managers and Professionals: An Exploratory Study
}

\author{
Ronald J. Burke ${ }^{1}$, Mustafa Koyuncu ${ }^{2}$, Parbudyal Singh ${ }^{1}$, Nihat Alayoglu ${ }^{3}$ \& Kadife Koyuncu ${ }^{2}$ \\ ${ }^{1}$ York University, Canada \\ ${ }^{2}$ Nevsehir University, Turkey \\ ${ }^{3}$ Istanbul Ticaret University, Turkey \\ Correspondence: Parbudyal Singh, School of Human Resource Management, York University, 4700 Keele Street, \\ Toronto, Ontario M3J 1P3, Canada. E-mail: singhp@yorku.ca
}

Received: November 28, 2011

Accepted: January 30, $2012 \quad$ Online Published: November 25, 2015

doi:10.5539/ijbm.v10n12p64

URL: http://dx.doi.org/10.5539/ijbm.v10n12p64

\begin{abstract}
This study explored the relationship among measures of Career Priority and Family Priority with a number of other variables including personal demographics, work situation characteristics, work motivations, work investments, work outcomes and indicators of psychological well-being. Data were collected for 94 men and 48 women in managerial and professional jobs working for different firms in different cities and various industrial sectors in Turkey. Career priority and Family priority were uncorrelated in this sample. Career priority was significantly correlated with several study measures. Managers indicating a higher Career priority were more satisfied and engaged in their jobs and indicated higher levels of psychological well-being. Somewhat surprisingly, Family priority was generally unrelated to these work and well-being outcomes.
\end{abstract}

Keywords: career priority, family priority, psychological well-being

\section{Introduction}

Individuals pursue multiple roles; the most important and certainly the most time consuming are family and work roles. Individuals also vary in the importance they attach to these roles, thus for some individuals work and career roles will be most important while for others family roles will be most important. The importance of work and family roles might change over time for some people, and vary in importance across countries and cultures (e.g., Burke, 2009; Hofstede, 2001).

In efforts to both understand and support the career advancement of women, Schwartz (1992) suggested that organizations should offer women with young children, if it is their preference, a less demanding role for a period of time so they can fill family obligations then returning to more demanding roles when their children get older. Women without children would continue to hold demanding jobs and careers similar to those held by ambitious men. She referred to the former as career-family women and the latter as career-primary women. Schwartz, perhaps as an oversight, did not make this same distinction among men.

Researchers have used the terms "career priority" and "family priority" to examine the importance or value of work and family roles. These concepts would apply to both women and men. These concepts have been operationalized in various ways by researchers as well. Burke and his colleagues (see Burke, 2001; 2000; Burke, Divinagracia \& Mamo, 1998; Burke, Kong \& McKeen, 19997; Burke, Koyuncu \& Fiksenbaum, 2007) studied career priority patterns of the type suggested by Schwartz in samples of managerial and professional women in five countries (Bulgaria, Canada, Norway, Singapore, and Turkey). In all cases, career priority patterns were measured by providing short paragraphs describing two professional women, one representing a career priority woman, the other representing a career-family woman. Managerial and professional women respondents, using a seven point scale, indicated which woman they were currently most like. These two groups were then compared on a number of measures such as personal demographics (e.g., age, marital status, education) and work situation characteristics (e.g., organizational level, income, job tenure), personality factors (e.g., Type A behavior, proactive personality), job behaviors (e.g. perfectionism), work outcomes (e.g., job and career satisfaction, intent to quit), and psychological well-being (e.g., exhaustion, psychosomatic symptoms). Women in four of the five countries were slightly more career-family priority than career-priority (Bulgaria, Canada, Norway, Singapore) 
while women in Turkey were slightly more career priority than career-family priority. In four of the five countries, career primary and career family priority women were generally similar on personal demographics and work situation characteristics (Bulgaria, Norway, Singapore and Turkey). In two countries, career priority women fared better on most work and well-being outcomes (e.g., Canada and Turkey). Career priority and career family priority women were generally similar on work and well-being outcomes in Bulgaria, Norway and Singapore.

Career priority and family priority have also been measured in a second way. This approach asks respondents to indicate how important career and work roles are in their lives, and how important family and family roles are in their lives (e.g., Lobel \& St. Clair, 1992). Career priority has been used as a predictor of satisfaction and well-being outcomes as well as a moderator of agreement in beliefs about career priority in dual earner couples on the support-exchange well-being relationship.

The present study examines correlates of career priority and family priority in a sample of male and female managers in Turkey. Turkey is a culture that places a very high value on family (Aycan, 2004). Would family priority then emerge as a stronger predictor of work and well-being outcomes than would career priority?

\section{Methods}

\subsection{Procedures}

All data were collected using anonymously completed questionnaires. The General Managers and Human Resource managers of 49 firms belonging to the Independent Industrialists and Business Association (MUSAID) completed the survey; all the firms are on the Top 1000 companies list of the Istanbul Chamber of Industry (ISO) in 2010. These firms were located in 17 different cities (mostly in Istanbul and Konya) and in ten industrial sectors (most in food, beverage and tobacco, and metals). These managers were asked to distributed surveys to 10 of their managers and professionals so as to increase the sample size. Seventeen firms declined to participate. A total of 142 completed questionnaires were received, the vast majority via e-mail, a $28 \%$ response rate. The sample is best described as a convenience sample.

\subsection{Respondents}

Demographic and work situation characteristics of the sample are shown in Table 1. The sample was mostly male $(66 \%)$, worked full-time $(99 \%)$, were married $(71 \%)$, had children $(69 \%) \mathrm{k}$, were between 31 and 40 years of age (56\%), had a Bachelor's university degree (70\%), earned over US $\$ 19,000(38 \%)$, has supervisory duties (79\%), worked in middle management (39\%), worked between 46 and 50 hours per week $(42 \%)$, had 5 years of less of organizational tenure (61\%), and 5 years of less of job tenure (75\%), and worked in organizations having 100-1000 employees (66\%). The latter suggests that most worked for small- and medium-sized enterprises.

Table 1. Demographic and work situation characteristics of the sample

\begin{tabular}{lll}
\hline Gender & $\underline{\mathrm{N}}$ & \% \\
\hline Male & 94 & 66.2 \\
Female & 48 & 33.8 \\
Work status & & \\
Full-time & 138 & 98.6 \\
$\begin{array}{l}\text { Part-time } \\
\text { Marital status }\end{array}$ & 2 & 1.4 \\
Single & & \\
Married & 41 & 29.1 \\
Children & 100 & 70.9 \\
Yes & & \\
No & 92 & 68.7 \\
Number of Children & 42 & 31.3 \\
1 & & \\
2 & 38 & 40.9 \\
3 or more & 41 & 46.1 \\
Education & 14 & 1 \\
Elementary & & \\
High School & 2 & 1.4 \\
Bachelors & 29 & 20.9 \\
Masters & 97 & 69.8 \\
PhD & 10 & 7.2 \\
Work hours & 1 & 0.7 \\
40 hours or less & & \\
\hline
\end{tabular}




\begin{tabular}{|c|c|c|}
\hline $41-45$ & 29 & 21.1 \\
\hline $46-50$ & 46 & 41.8 \\
\hline $51-55$ & 22 & 16 \\
\hline $56-60$ & 22 & 15.9 \\
\hline 61 or more & 11 & 8 \\
\hline \multicolumn{3}{|l|}{ Organizational Tenure } \\
\hline 2 years or less & 37 & 26.4 \\
\hline $3-5$ years & 45 & 32.2 \\
\hline $6-10$ years & 40 & 28.5 \\
\hline 11 years or more & 18 & 12.9 \\
\hline \multicolumn{3}{|l|}{ Age } \\
\hline 25 years or less & 14 & 10.1 \\
\hline $26-30$ & 30 & 21.8 \\
\hline $31-35$ & 40 & 29 \\
\hline $36-40$ & 38 & 27.3 \\
\hline 41 or more & 16 & 11.6 \\
\hline \multicolumn{3}{|l|}{ Length of marriage } \\
\hline 5 years or less & 36 & 33.6 \\
\hline $6-10$ years & 28 & 26.2 \\
\hline $11-15$ years & 28 & 26.2 \\
\hline 16 or more years & 15 & 14 \\
\hline \multicolumn{3}{|l|}{ Income } \\
\hline US $\$ 7,000$ or less & 17 & 12.5 \\
\hline $7,000-9,999$ & 10 & 7.4 \\
\hline $10,000-12,999$ & 16 & 11.8 \\
\hline $13,000-15,999$ & 22 & 16.2 \\
\hline $16,000-18,999$ & 20 & 14.7 \\
\hline US\$ 19,000 or more & 51 & 37.5 \\
\hline \multicolumn{3}{|l|}{ Supervisory duties } \\
\hline Yes & 105 & 78.9 \\
\hline No & 28 & 21.1 \\
\hline \multicolumn{3}{|l|}{ Organizational Level } \\
\hline Non-management & 34 & 24.8 \\
\hline Lower management & 29 & 21.2 \\
\hline Middle management & 54 & 39.4 \\
\hline Senior management & 20 & 14.6 \\
\hline \multicolumn{3}{|l|}{ Job tenure } \\
\hline 2 years or less & 56 & 39.1 \\
\hline $3-5$ years & 49 & 35.5 \\
\hline $6-10$ years & 31 & 22.5 \\
\hline 11 or more years & 4 & 2.9 \\
\hline \multicolumn{3}{|l|}{ Organizational size } \\
\hline 100 or less & 28 & 20.9 \\
\hline $101-500$ & 48 & 35.8 \\
\hline $501-1000$ & 41 & 30.6 \\
\hline 1001 or more & 17 & 12.7 \\
\hline
\end{tabular}

\subsection{Measures}

Personal and demographic and work situation characteristics were measured by single items (see Table 1). These included: gender, age, marital and parental status, work status, level of education, income, job and organizational tenure, and organizational size.

\subsubsection{Career Priority and Family Priority}

Career priority and Family priority were each measured by two items ( $\alpha=.82$ and $\alpha=.93$, respectively) developed by Lobel and St. Clair (1992). Items included "The most important things that happen to me involve my career" and "The most important things that happen to me involve my family."

\subsubsection{Job Demands}

Two job demands were considered. Work hours was measured by a single item "How many hours do you work in a typical week?" Work intensity was measured by a 15 item scale $(\alpha=.71)$ based on items proposed by Hewitt and Luce (2006) and Burke, Singh and Fiksenbaum (2010). Items included "an unpredictable flow of work", "fast-paced work under tight deadlines", and "routinely receive work-related phone calls and e-mails at home." 


\subsubsection{Work Motivations}

Two work motivations underlying one's work investment were examined: Passion and Addiction. Passion was measured by a 19 item scale $(\alpha=.84)$ containing items from several sources (e.g., Hadley, 2008; Perttula, 2009; Cardon, Wincent, Singh \& Drnovsek, 2009). One item was "My work is a part of who I am." Addiction was measured by a 6 item scale $(\alpha=.74)$ developed by Spence and Robbins (1992). One item was "I often feel that there's something inside me that drives me to work hard."

\subsubsection{Work Outcomes}

Five work outcomes were assessed. Job satisfaction was measured by a 6 -item scale $(\alpha=.71)$ developed by Kofodimos (1993). One item was "I feel challenged by my work". Intent to quit was measured by a two item scale $(\alpha=.75)$ used previously by Burke (1991). An item was "Are you currently looking for a different job in a different organization? (yes/no). Three components of work engagement developed by Schaufeli, Salanova, Gonzalez-Roma and Bakker (2002) were used. Vigor was measured by 6 items $(\alpha=.84)$. One item was "At my work, I feel bursting with energy." Dedication was assessed by 5 items $(\alpha=.89)$. An item was "My job inspires me." Absorption was measured by 6 items $(\alpha=.68)$. One item was "I am immersed in my work."

\subsubsection{Psychological Well-Being}

Three aspects of psychological well-being were included. Exhaustion was measured by a 9 item scale $(\alpha=.78)$, part of the Maslach Burnout Inventory (Maslach, Jackson, \& Leiter, 1996). One item was "I feel burned out from my work." Psychosomatic symptoms was assessed by a 19 item scale $(\alpha=.90)$ developed by Quinn and Shepard (1974). Respondents indicated how often each symptom happened to them in the past year. Items included "cramps in my legs", "poor appetite" and "having trouble getting to sleep". Life satisfaction was assessed by a 5item scale $(\alpha=.87)$ developed by Diener, Emmons, Larsen, and Griffin (1985). An item was "I am satisfied with my life."

\section{Results}

\subsection{Descriptive Statistics}

Career priority and Family priority were not correlated in this sample $(r=-.03$, ns, $n=140)$. Managers gave significantly higher priority to Family than to Careers (means and s.d's being 4.2 and 1.01, $\mathrm{n}=139$, and 5.8, 104, $\mathrm{n}=139, \mathrm{p}<.001$, respectively).

\subsection{Correlates of Career Priority and Family Priority}

Table 2 presents the correlations between levels of both Career Priority and Family Priority with other variables in the study. The sample sizes for the correlations reported here range from 121 to 140.

Table 2. Correlates of career priority and family priority

\begin{tabular}{lrr}
\hline & Career Priority & Family Priority \\
\hline Personal demographics & & -.01 \\
Gender & .14 & .04 \\
Age & -.05 & .11 \\
Work status & $.14 \mathrm{a}$ & $.15 \mathrm{a}$ \\
Parental status & $-.37^{* * *}$ & -.00 \\
Education & .02 & .04 \\
Income & .02 & .04 \\
Work situation characteristics & & -.14 \\
Organizational level & .06 & -.01 \\
Supervisory duties & -.00 & $.16 \mathrm{a}$ \\
Organizational tenure & $-.25^{* * *}$ & .11 \\
Job tenure & $-.41^{* * *}$ & -.10 \\
Organizational size & & $.19^{*}$ \\
Work motivations & .46 & .09 \\
Passion & .04 & .04 \\
Addiction & & .02 \\
Work investments & & \\
Work hours & .01 & \\
Work intensity & -.08 & \\
\hline
\end{tabular}




\begin{tabular}{lrr}
\hline Expected hours - supervisor & $-.16 \mathrm{a}$ & .04 \\
Expected hours - co-workers & .06 & .02 \\
Work outcomes & $.21^{*}$ & -.04 \\
Job satisfaction & .06 & -.04 \\
Intent to quit & $.24^{*}$ & -.02 \\
Vigor & $.33^{* * *}$ & -.03 \\
Dedication & $.20^{*}$ & .05 \\
Absorption & &. .17 \\
Psychological well-being & $-.25^{* *}$ & .07 \\
Exhaustion & $.14 \mathrm{a}$ & .10 \\
Psychosomatic symptoms & & -.05 \\
Life satisfaction & & \\
\hline
\end{tabular}

$* * * \mathrm{p}<.001 ; * * \mathrm{p}<.01 ; *_{\mathrm{p}}<.05 ;$ a $\mathrm{p}<.10$.

\subsection{Career Priority, Family Priority and Personal Demographic Characteristics}

The top fifth of Table 2 shows the correlations between Career Priority and Family Priority and personal demographics. Career priority was rated lower among married respondents and tended to be lower among respondents with children $(\mathrm{p}<.10)$; married respondents tended to give a higher value to Family priority $(\mathrm{p}<.10)$.

\subsection{Career Priority, Family Priority and Work Situation Characteristics}

Managers having longer organizational and job tenures indicated less Career priority, managers having longer job tenure also tended to report higher levels of family priority.

\subsection{Career Priority, Family Priority and Work Motivations}

Managers indicating higher levels of Passion also reported higher levels of both Career priority and Family priority.

\subsection{Career Priority, Family Priority and Work Investment}

Both Career priority and Family priority were unrelated to most measures of work investment (e.g., work hours, perceptions of work intensity, work hours expected by both supervisors and co-workers); managers having a higher Career priority tended to indicate a lower expectation of hours on the part of their supervisors $(\mathrm{p}<.10)$.

\subsection{Career Priority, Family Priority and Work Outcomes}

Managers indicating higher levels of Career priority also reported higher levels of job satisfaction, vigor, dedication and absorption.

\subsection{Career Priority, Family Priority and Psychological Well-Being}

Managers reporting higher levels of Career priority indicated lower levels of exhaustion and fewer psychosomatic symptoms and tended to report higher life satisfaction.

Overall, three observations are worth noting. First, respondents attached significantly higher priority to Family than to Career. Second, Career priority was related to considerably more study variables than was Family Priority. Third, higher levels of Career Priority tended to be related to more favorable work and well-being outcomes.

\section{Discussion}

This study explored the relationship of manager's career priority and family priority with a variety of personal demographics, work situation characteristics, work motivations and work investments, work outcomes and indicators of psychological well-being. The findings were somewhat unexpected in that Family priority was related to very few variables while Career priority was related to considerably more. And managers having higher Career priorities indicated higher levels of work satisfaction and engagement and greater psychological health. These findings were consistent with those found in studies of career priority and career-family priority among women managers and professionals reported above.

Why was career priority correlated with many more work and well-being outcomes than was family priority in a culture that places a high value on family? Consistent with suggested cultural priorities (see Aycan, 2004), women and men in our study attached significantly higher priority to family than to career. How can one "explain" some of these unexpected and inconsistent results? The sample was relatively young and had relatively low levels of both job and organizational tenure. Respondents worked considerable hours per week in jobs of 
moderate intensity. It may be that respondents, however, attached high priority to family as reflected in societal values, while individually placing higher values on their work and careers.

\subsection{Limitations of the Research}

Some limitations of the research should be noted to put the findings into a broader context. First, all data were collected using self-report questionnaires raising the possibility of response set tendencies. Second, the sample, best described as a convenience sample, may not be representative of Turkish managers and professionals. For example this sample was relatively young and had relatively short job and organizational tenures. Third, the sample of female managers and professionals was relatively small $(n=48)$. Fourth, males and females were combined to yield a larger sample making it impossible to consider correlates of career priority and family priority separately for them. Fifth, the study did not determine the employment status of spouses; it was likely that spouses of married female managers were employed but it is not clear how many of the male mangers had spouses that worked outside the home for pay.

\subsection{Future Research Directions}

It would be useful to include a larger sample of female managers and professionals in future work. This would make it possible to examine correlates separately for females and males. In addition, obtaining respondents' perceptions of perceived bias, discrimination and challenges would add to our understanding of women's work experiences and satisfactions. Finally, it would be informative to add "objective" measures of the performance of female and male managers and professionals to complement the more readily available self-reports of employees.

\section{Acknowledgements}

This research was supported in part by York University, Nevsehir University, Istanbul Ticaret University and a research grant from the Social Science and Humanities Research Council of Canada. We acknowledge the participation of the organizations and our respondents.

\section{References}

Aycan, Z. (2004). Key success factors for women in management in Turkey. Applied Psychology: An International Review, 53, 453-477. http://dx.doi.org/10.1111/j.1464-0597.2004.00180.x

Burke, R. J. (1991). Early work and career experiences of female and male managers and professionals: Reasons for optimism? Canadian Journal of Administrative Sciences, 8, 224-230. http://dx.doi.org/10.1111/j.1936-4490.1991.tb00565.x

Burke, R. J. (2000). Career priority patterns among managerial women: A study of four countries. Psychological Reports, 86, 1264-1266. http://dx.doi.org/10.2466/pr0.2000.86.3c.1264

Burke, R. J. (2001). Managerial women's career experiences, satisfaction and well-being: A five country study. Cross Cultural Management, 8, 117-133. http://dx.doi.org/10.1108/13527600110797254

Burke, R. J. (2009). Cultural values and women's work and career experiences. In R. Bhagat \& R. M. Steers (Eds.), Culture, organizations, and work (pp. 442-461). Cambridge: Cambridge University Press. http://dx.doi.org/10.1017/CBO9780511581151.017

Burke, R. J., Divinagracia, L. A., \& Mamo, E. (1998). Use of career strategies by Filipino managerial women. Women in Management Review, 13, 217-220. http://dx.doi.org/10.1108/09649429810232164

Burke, R. J., Kong, Y. P., \& McKeen, C. A. (1997). Managerial and professional women in Canada and Singapore. The Asian Manager, 10, 78-82.

Burke, R. J., Koyuncu, M., \& Fiksenbaum, L. (2007). Career priority patterns among managerial and professional women in Turkey. Women in Management Review, 22, 405-417. http://dx.doi.org/10.1108/09649420710761464

Burke, R. J., Singh, P., \& Fiksenbaum, L. (2010). Work intensity: Potential antecedents and consequences. Personnel Review, 39, 347-360. http://dx.doi.org/10.1108/00483481011030539

Cardon, M., Wincent, J., Singh, J., \& Drnovsek, M. (2009). The nature and experience of entrepreneurial passion. Academy of Management Review, 34, 511-532. http://dx.doi.org/10.5465/AMR.2009.40633190

Diener, E., Emmons, R. A., Larsen, R. J., \& Griffin, S. (1985). The satisfaction with life scale. Journal of Personality Assessment, 49, 71-75. http://dx.doi.org/10.1207/s15327752jpa4901_13

Hadley, C. N. (2008). What does it mean to love a job? In R. J. Burke \& C. L. Cooper (Eds.), The long work 
hours culture: Causes, consequences and choices (pp. 37-60). Bingley, UK: Emerald.

Hewlett, S. A., \& Luce, C. B. (2006). Extreme jobs: the dangerous allure of the 70 hour work week. Harvard Business Review, 49-59.

Hofstede, G. (2001). Culture's consequences: Comparing values, behaviors and organizations across nations. Thousand Oaks, CA: Sage Publications.

Kofodimos, J. (1993). Balancing act. San Francisco: Jossey-Bass.

Lobel, S., \& St. Clair, L. (1992). Effects of family responsibilities, gender, and career identity salience on performance outcomes. Academy of Management Journal, 5, 1057-1069. http://dx.doi.org/10.2307/256540

Maslach, C., Jackson, S. E., \& Leiter M. P. (1996). Maslach Burnout Inventory (3rd ed.). Palo alto, CA: Consulting Psychologists Press.

Quinn, R. P., \& Shepard, L. (1974). The 1972-1973 Quality of Employment Survey. Institute for social Research, University of Michigan, Ann Arbor, MI.

Schaufeli, W. B., Salanova, M., Gonzalez-Roma, V., \& Bakker, A. B. (2002). The measurement of engagement and burnout: A two-sample confirmatory factor-analytic approach. Journal of Happiness Studies, 3, 71-92. http://dx.doi.org/10.1023/A:1015630930326

Schwartz, F. N. (1992). Breaking with tradition: Women and work, the new facts of life. New York: Warner.

Spence, J. T., \& Robbins, A. S. (1992). Workaholism: Definition, measurement, and preliminary results. Journal of Personality Assessment, 58, 160-178. http://dx.doi.org/10.1207/s15327752jpa5801_15

\section{Copyrights}

Copyright for this article is retained by the author(s), with first publication rights granted to the journal.

This is an open-access article distributed under the terms and conditions of the Creative Commons Attribution license (http://creativecommons.org/licenses/by/3.0/). 